\title{
Formação educacional e profissional e sucesso no mercado de trabalho: o caso dos imigrantes portugueses na Holanda
}

\author{
Educational and professional background and \\ success in the labor market: the case of Portuguese \\ immigrants in the Netherlands
}

\section{Parcours scolaire et professionnel et la réussite sur le marché du travail: le cas des immigrants portugais aux Pays-Bas}

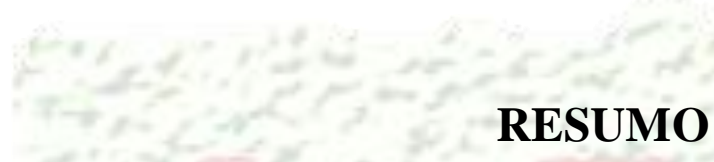

Silvana Fernandes LOPES

\section{RESUMO}

O objetivo deste artigo é descrever a relação entre as trajetórias de educação e de ocupação profissional dos imigrantes portuguesès na Holanda. Para tal, foi utilizada uma amostra constituída por portugueses que chegaram à Holanda nos dois períodos que representam o maior afluxo de imigrantes: por volta dos anos 1966 e 2002. A análise dos dados mostra uma forte relação entre o nível de formação educacional e profissional e o de ocupação laboral. Além disso, as exceções encontradas contribuem para demonstrar que a formação em serviço pode aumentar as possibilidades de ascensão no que respeita à ocupação profissional.

Palavras-chave: educaȩão profissional, ocupaçâo profissional; reconversão profissional; mercado de trabalho.

\begin{abstract}
The aim of this paper is to describe the relationship between educational and professional occupation trajectories of Portuguese immigrants in The Netherlands. To this end, the sample used comprises Portuguese immigrants that arrived in The Netherlands in two periods which represent the highest influx of immigrants: around the years 1966 and 2002. The analysis of the data shows a strong relationship between the level of professional education and the level of professional occupation. Furthermore, some exceptions to the generalizations found show that in service training may lead to an improvement of the possibilities to ascend regarding the level of professional occupation.
\end{abstract}


Index terms: professional education; professional occupation; professional reorientation; labor market.

\section{RÉSUMÉ}

Cet article se propose de décrire la relation entre les trajectoires de l'éducation et des activités professionnelles des immigrants portugais aux Pays-Bas. À cette fin, on a utilisé un échantillon d'immigrants portugais arrivés aux Pays-Bas en deux périodes qui représentent les plus grands afflux, aux alentours de 1966 et de 2002. L'analyse des données montre une relation forte entre le niveau de scolarisation et de professionalisation et le niveau du travail. En outre, les exceptions rencontrées contribuent à démontrer que la formation en cours d'emploi peut augmenter les chances d'évolution professionnelle.

Mots-clef: Formation professionnelle; activité professionnelle; reorientation professionnelle; marché du travail.

\section{Introdução}

Este artigo tem como objetivo estabelecer a relação entre o nível de formação educacional e profissional e o tipo de ocupação profissional dos imigrantes portugueses na Holanda. Para tal, a apresentação deste trabalho está organizada nas seguintes seções: 1. A imigração portuguesa na Holanda; 2. A metodologia e a amostra; 3. Formação educacional e profissional e ocupação profissional; e 4. Conclusão.

\section{A imigração portuguesa na Holanda}

A emigração faz parte da história dos portugueses (SERRÃO, 1977; GODINHO, 1978; PEREIRA, 1981; ARROTEIA, 1983; ROCHATRINDADE, 1986). Desde o século XV, os portugueses têm se espalhado pelo mundo, por razões distintas, dispersando-se por diferentes países. Até a década de 1960, a emigração portuguesa ocorreu predominantemente para os países transoceânicos, como Brasil, Estados Unidos, Canadá e Venezuela. A partir dessa década, a emigração voltou-se para o continente 
europeu, principalmente para a França, mas também para a Alemanha, Suíça, Reino Unido e Luxemburgo. O fluxo emigratório foi se modificando ao longo do tempo, apresentando uma queda nas décadas de 1980 e 1990, para depois tornar a aumentar por meio de uma nova modalidade, a do trabalho temporário. Além dos destinos principais, já citados, os portugueses estavam e/ou estão presentes em praticamente todas as partes do mundo e, dentre elas, a Holanda. Do ponto de vista quantitativo, o número de portugueses nesse país é limitado. Em 2004 (CENTRAAL BUREAU VOOR DE STATISTIEK, 2004) havia 16,3 milhões de habitantes na Holanda, dos quais 3,1 milhões eram alóctones. Desses, por exemplo, aproximadamente 350 mil eram turcos, enquanto a populaçãa portuguesa era de 17 mil habitantes.

As informações estatísticas referentes ao crescimento demográfico na Holanda mostram que a emigração portuguesa atingiu um pico em meados dos anos sessenta, outro no início dos anos 2000 e novamente em 2007. Esse movimento migratório foi relativamente idêntico àquele observado em diversos países europeus economicamente mais desenvolvidos (CENTRAAL BUREAU VOOR DE STATISTIEK, 19952007).

Na_Tabela 1 são apresentados os dados quantitatiyos disponíveis sobre os imigrantes portugueses na Holanda. Nela não constam as informações referentes ao período compreendido entre 1989 e 1994 porque os relatórios demográficos desse período fornecem dados relativos à emigração portuguesa apenas para a Alemanha, Espanha, França, Reino Unido, Bélgica, Suíça e “outros países europeus". O fato de não se destacar a Holanda, incluindo-a nessa última categoria, é uma forte indicação de que a emigração para esse país não foi expressiva no período. Parece claro, então, que os picos de emigração portuguesa para a Holanda foram os anos de 1966, 2002 e 2007 e são os dois primeiros desses picos que são tomados como pontos de referência neste artigo. 
Tabela 1 - Imigrantes portugueses na Holanda no período de 1950 a 2007

\begin{tabular}{|c|c|c|c|}
\hline Ano & Imigrantes & Ano & Imigrantes \\
\hline 1950 & 4 & 1979 & 25 \\
\hline 1951 & 2 & 1980 & 38 \\
\hline 1952 & 2 & 1981 & 50 \\
\hline 1953 & 3 & 1982 & 12 \\
\hline 1954 & 4 & 1983 & 15 \\
\hline 1955 & 4 & 1984 & 17 \\
\hline 1956 & 8 & 1985 & 13 \\
\hline 1957 & 8 & 1986 & 18 \\
\hline 1958 & 6 & 1987 & 13 \\
\hline 1959 & 2 & 1988 & 15 \\
\hline 1960 & 3 & 1989 & - \\
\hline 1961 & 55 & 1990 & \\
\hline 1962 & 70 & 1991 & \\
\hline 1963 & 148 & 1992 & \\
\hline $\begin{array}{l}1964 \\
1965\end{array}$ & $\begin{array}{l}297 \\
480\end{array}$ & $\begin{array}{l}1993 \\
1994\end{array}$ & \\
\hline 1966 & 1308 & 1995 & 739 \\
\hline 1967 & 401 & 1996 & 810 \\
\hline 1968 & 407 & 1997 & 868 \\
\hline 1969 & 420 & 1998 & 1021 \\
\hline 1970 & 393 & 1999 & 1216 \\
\hline 1971 & 338 & 2000 & 1434 \\
\hline 1972 & 149 & 2001 & 1643 \\
\hline 1973 & 394 & 2002 & 1653 \\
\hline 1974 & 287 & 2003 & 1619 \\
\hline 1975 & 44 & 2004 & 1349 \\
\hline 1976 & 19 & 2005 & 1258 \\
\hline 1977 & 34 & 2006 & 1696 \\
\hline 1978 & 19 & 2007 & 2096 \\
\hline
\end{tabular}

Fonte: Ribeiro (1986) e Centraal Bureau voor de Statistiek (1995-2007).

De acordo com Franco (1974, p. 17), o fluxo emigratório português na década de 1960 absorveu os excedentes demográficos, reduzindo a população total de Portugal em 2\% entre 1961 e 1971. A maioria desses portugueses dirigiu-se para a França, como já foi mencionado, porém alguns deles emigraram para a Holanda. Esse país, em 1963, estabeleceu acordos com Portugal para recrutamento de trabalhadores. No entanto, como observou Lindo (2000, p. 128), foi necessário algum tempo para que a 
emigração portuguesa para a Holanda aumentasse e somente em 1966 o número ultrapassou a casa de mil emigrantes.

Apesar da falta de informações estatísticas mais detalhadas, pode-se observar que a maioria dessas pessoas estava em situação de desemprego, de subemprego ou exercendo trabalhos manuais mal remunerados em Portugal, buscando na Holanda, então, oportunidades que não encontravam em seu país. Do ponto de visto educacional, Lindo (2000, p. 130) mostra que mais de $80 \%$ desses emigrantes tinha completado, no máximo, a educação primária em Portugal.

Dentre esses portugueses, uma parte escolheu a Holanda devido a laços familiares ou de amizade com pessoàs já residentes no país ou a contratos de trabalho com empresas holandesas, como a companhia dérea KLM e os diferentes estaleiros navais no Porto de Roterdã. Outra parte desses emigrantes foi para a Holanda como refugiado político, tentando escapar da participação nas guerras coloniais. Aparentemente, a maioria desses refugiados tinha uma formação educacional e profissional mais elevada e regressou a Portugal após a Revolução dos Cravos, em 1974.

Como demonstra Lindo (2000, p. 129), a maioria dos emigrantes de 1966 reunia seus familiares pouco tempo depois da chegada do chefe da família à_Holanda e mais da metade deles trazia suas esposas no prazo de um ano. Dessa forma, uma característica marcante era a emigração familiar.

Já no início dos anos 2000, assim como em outros países, o perfil do emigrante português para a Holanda tornou-se mais heterogêneo. Dentro desse grupo, há uma série de diferenças quanto às condições de vida em Portugal. Boa parte deles tinha emprego (ou subemprego) em seu país, porém resolveu "aventurar-se" visando acumular dinheiro em um curto espaço de tempo e depois retornar à sua terra natal. Outros, desempregados, emigraram em busca de um trabalho temporário e foram migrando pelos países europeus na medida em que os seus contratos terminavam. Ainda outro grupo, muito diferente dos anteriores, era formado por jovens que se 
deslocaram para a Holanda com o objetivo de continuar e aperfeiçoar seus estudos e assim encontrar alternativas profissionais mais atrativas nos países mais desenvolvidos. A despeito dessas diferenças, a característica comum era a emigração individual.

Segundo dados da Organização para a Cooperação e Desenvolvimento Econômico (OCDE), no período de 2000 a 2006 houve um aumento da emigração portuguesa para cinco países da Europa: Espanha, Suíça, Luxemburgo, Bélgica e Holanda. Esses países teriam sido escolhidos por apresentarem taxas de crescimento econômico superior às de Portugal e escassez de mão de obra com alguma qualificação (INTERNATIONAL MIGRATION OUTLOOK, 2008).

\section{A metodologia e a amostra}

A partir dos dados já apresentados, foi constituída uma amostra de imigrantes que chegaram na Holanda dentro dos dois períodos selecionadós (1966 e 2002) por serem os anos de maior confluência de emigrantes portugueses.

Em função da necessidade de se incluir um número suficiente de informantes, a amostra foi ampliada para cinco anos antes e depois dos anos de referênéia e,-doravante, será denominado o primeiro grupo como a geração de 1966 e o segundo como a geração de 2002.

Fazendo uso de um questionário sistemático, foram entrevistados 30 informantes assim distribuídos: 20 que emigraram para Amsterdã (dos quais 10 da geração de 1966 e 10 da de 2002) e 10 que emigraram para Roterdã (distribuídos em 05 para a geração de 1966 e 05 para a de 2002). Essa divisão entre cidades foi baseada na disponibilidade de informantes em função do tamanho dos grupos de imigrantes nelas residentes.

Dado o tamanho reduzido da comunidade portuguesa na Holanda, os informantes foram assim localizados: i) nas Associações Portuguesas que 
servem como pontos de encontro de pessoas dessa nacionalidade ("Os Lusitanos" e "Associação Portuguesa de Amsterdam", ambas sediadas em Amsterdã, e o "Centro Português de Rotterdam", em Roterdã); ii) em algumas instituições de apoio a imigrantes ("Basisberaad" e o "Donadaria", as duas sediadas em Roterdã); e iii) por meio de indicações dos próprios informantes.

Os dados básicos das pessoas que compõem a amostra são apresentados na Tabela 2 .

Cabe destacar que os códigos utilizados para identificar os (grupos de) informantes são os seguintes: $\mathrm{I}$ = geração de 1966, II = geração de 2002; $\mathrm{A}=$ Amsterdã, $\mathrm{R}=$ Roterdã; número = identificação individual dos informantes dentro de cada geração por cidade.

Com o objetivo de ilustrar essa amostra, antes de apresentar os dados quantitativos serão descritos alguns exemplos de imigrantes da geração de 1966 e da geração de 2002. Esses exemplos podem ser considerados típicos para os dois picos de emigração de portugueses para a Holanda.

(1) O/A informante IA01 concluiu quatro anos de educação primária em Portugal. Começou a trabalhar ainda jovem, com 12 anos, como aprendiz, desempenhando tarefas rotineiras de auxiliar em diferentes locais. Emigrou para a Holanda em busca de condições melhores de vida. Um parente havia lhe arranjado um trabalho no setor de frete da KLM. Segundo ele, trabalhavam nessa empresa por volta de 120 portugueses na época e era possível comunicar-se utilizando somente a língua portuguesa. Ficou nesse emprego até a sua aposentadoria.

(2) O/A informante IR01 concluiu quatro anos da educação primária em Portugal. Começou a trabalhar com 11 anos como aprendiz de serralheiro, mudando de local de trabalho muitas vezes. Com 18 anos passou para $1^{\circ}$ Oficial em serralheria civil e ganhava melhor porque era especializado. Emigrou para a Holanda para ganhar mais dinheiro e também em razão do sistema político vigente em Portugal na época. Um amigo português que 
trabalhava em um estaleiro naval em Roterdã arranjou-lhe um emprego, no qual ele permaneceu até a aposentadoria.

(3) O/A informante IA05, depois de completar a educação secundária em Portugal, emigrou para a Holanda como refugiado político. Na Holanda, cursou a graduação e a pós-graduação, concluindo o doutoramento. É professor universitário.

(4) O/A informante IIA09 concluiu o $2^{\circ}$ ciclo em Portugal. Começou a trabalhar com 13 anos, mudando de emprego várias vezes na medida em que conseguia uma proposta salarial melhor, variando também o tipo de ocupação profissional. Depois de trabalhar dessa forma por 16 anos, foi para a Holanda visando acumular dinheiro em pouco tempo e quitar a casa comprada em Portugal. Um amigo que trabalhava em uma empresa engarrafadora de vinhos arranjou-lhe o emprego. Nele pode falar em português porque há vários portugueses que lá trabalham.

(5) O/A informante IIR03 concluiu a educação profissional (ensino secundário técnico) em Portugal. Depois de atuar como serralheiro durante 15 anos em diferentes empresas naquele país, passou a trabalhar em refinarias na Suécia, Holanda, Alemanha e França, com contratos temporários. Ia e vinha de Portugal, emigrando definitivamente para a Holanda 5 anos depois porque ficou desempregado e tinha antigos amigos da escola que trabalhavam como serralheiros em Roterdã. Conseguiu, então, junto a um empreiteiro português, emprego de serralheiro em diversas refinarias e centrais termoelétricas. Desde o início de 2007 trabalha como empregado fixo em um estaleiro. Fez alguns cursos de formação em serviço, especializando-se como tubista.

(6) O/A informante IIA05 fez o curso de canto profissional no conservatório e trabalhou em alguns coros enquanto cursava o ensino superior em Portugal. Abandonou o curso e foi para Amsterdã com o objetivo de aperfeiçoar-se em canto. Escolheu a Holanda porque tinha amigos que lhe arranjaram um lugar para morar. Concluiu o curso de canto no 
Conservatório de Amsterdã, onde estudam cerca de 50 alunos portugueses, e trabalhou em diversos coros da cidade para pagar parte dos estudos. Trabalha como solista free-lance.

Tabela 2 - Composição da amostra

\begin{tabular}{|c|c|c|c|c|c|c|}
\hline Informante & Cidade & $\begin{array}{l}\text { Ano de } \\
\text { imigração }\end{array}$ & $\begin{array}{l}\text { Ano de } \\
\text { nasci- } \\
\text { mento }\end{array}$ & Sexo & $\begin{array}{l}\text { Distrito de } \\
\text { nasci- } \\
\text { Mento }\end{array}$ & $\begin{array}{l}\text { Distrito } \\
\text { antes da } \\
\text { imigração }\end{array}$ \\
\hline IA01 & Amsterdã & 1969 & 1941 & Masc. & Santarém & Lisboa \\
\hline IA02 & Amsterdã & 1970 & 1948 & Masc. & Lisboa & Lisboa \\
\hline IA03 & Amsterdã & 1964 & 1937 & Masc. & Lisboa & Lisboa \\
\hline IA04 & Amsterdã & 1970 & 1942 & Masc. & Braga & Lisboa \\
\hline IA05 & Amsterdã & 1970 & 1944 & Masc. & Beja & Lisboa \\
\hline IA06 & Amsterdã & 1966 & 1940 & Masc. & Lisboa & Lisboa \\
\hline IA07 & Amsterdã & 1965 & 1943 & Fem. & Lisboa & Lisboa \\
\hline IA08 & Amsterdã & 1970 & 1949 & Fem. & Lisboa & Lisboa \\
\hline IA09 & Amsterdã & 1962 & 1925 & Masc. & Lisboa & Lisboa \\
\hline IA10 & Amsterdã & 1966 & 1927 & Masc. & Vila Real & Lisboa \\
\hline IR01 & Roterdã & 1965 & 1936 & Masc. & Lisboa & Lisboa \\
\hline IR02 & Roterdã & 1970 & 1941 & Fem. & Faro & Faro \\
\hline IR03 & Roterdã & 1965 & 1934 & Masc. & Lisboa & Lisboa \\
\hline IR04 & Roterdã & 1966 & 1941 & Masc. & Beja & Lisboa \\
\hline IR05 & Roterdã & 1962 & 1934 & Masc. & Évora & Lisboa \\
\hline IIA01 & Amsterdã & 2004 & 1980 & Masc. & Santarém & Santarém \\
\hline IIA02 & Amsterdã & 2000 & 1953 & Masc. & Setúbal & Setúbal \\
\hline IIA03 & Amsterdã & 2002 & 1980 & Masc. & Coimbra & Coimbra \\
\hline IIÁ04 & Amsterdã & 2001 & 1959 & Masc. & Lisboa & Lisboa \\
\hline IIA05 & Amsterdã & 2001 & 1973 & Masc. & Lisboa & Lisboa \\
\hline IIA06 & Amsterdã & 2001 & 1976 & Masc. & Porto & Porto \\
\hline IIA07 & Amsterdã & 2002 & 1955 & Fem. & Portalegre & Portalegre \\
\hline HА08 & Amsterdã & 2002 & 1977 & Fem. & Lisboa & Lisboa \\
\hline IIA09 & Amsterdã & 2005 & 1976 & Masc. & Porto & Porto \\
\hline IIA10 & Amsterdã & 2003 & 1978 & Fem. & Lisboa & Lisboa \\
\hline IIR01 & Roterdã & 1999 & 1953 & Masc. & Guarda & Lisboa \\
\hline IIR02 & Roterdã & 2001 & 1948 & Masc. & Vila Real & Vila Real \\
\hline IIR03 & Roterdã & 2005 & 1961 & Masc. & Lisboa & Lisboa \\
\hline IIR04 & Roterdã & 2001 & 1975 & Masc. & Lisboa & Lisboa \\
\hline IIR05 & Roterdã & 2001 & 1974 & Fem. & Setúbal & Setúbal \\
\hline
\end{tabular}

\section{Formação educacional e profissional e ocupação profissional}

\subsection{Os dados}


$\mathrm{Na}$ Tabela 3 são apresentados os dados referentes à formação educacional e profissional e ao nível de emprego dos imigrantes que compõem a amostra, organizados segundo o número de anos dedicados à formação que não fosse primária/secundária, ou seja, à formação específica para o exercício de uma profissão. As informações contidas nessa tabela são as seguintes:

Coluna 1: Código do informante, como explicado em relação à Tabela 2;

Coluna 2: Número de anos de educação primária/secundária que o informante concluiu (essa categorização bastante genérica é necessária pois a organização do sistema educativo em Portugal mudou entre os dois períodos estudados e, portanto, os membros da primeira e da segunda geração estudaram segundo estruturas de ensino diferentes);

Coluna 3: Número de anos de educação profissional que o informante completou, definida como o tipo de ensino que se destina à preparaçấo para uma ocupação laboral específica;

Coluna 4: Número de anos de ensino superior que o informante completou. Foi adicionado um "D" quando o informante obteve o título de doutorado; Coluna 5: Número de anos dedicados à formação em serviço (especificicado em anos e meses, separados por um ponto e vírgula);

Coluna 6: Número de anos de educação, excluindo a educação primária/secundária, especificado em anos e meses, separados por um ponto e vírgula. Isso equivale à soma total das colunas 3, 4 e 5 e corresponde à formação profissional;

Coluna 7: Nível de emprego no momento da entrevista, classificado de acordo com uma versão reduzida da International Standard Classification of Occupations (1988). A classificação utilizada tem as seguintes categorias:

A: um trabalho que consiste na execução de tarefas simples e rotineiras;

B: um trabalho que requer experiência e compreensão de um equipamento específico ou de um processo específico; 
C: um trabalho que exige a compreensão de todas as etapas do processo de produção ou de administração;

D: um trabalho que é essencialmente de natureza científica ou intelectual.

Tabela 3 - Formação educacional e profissional e nível de emprego dos informantes

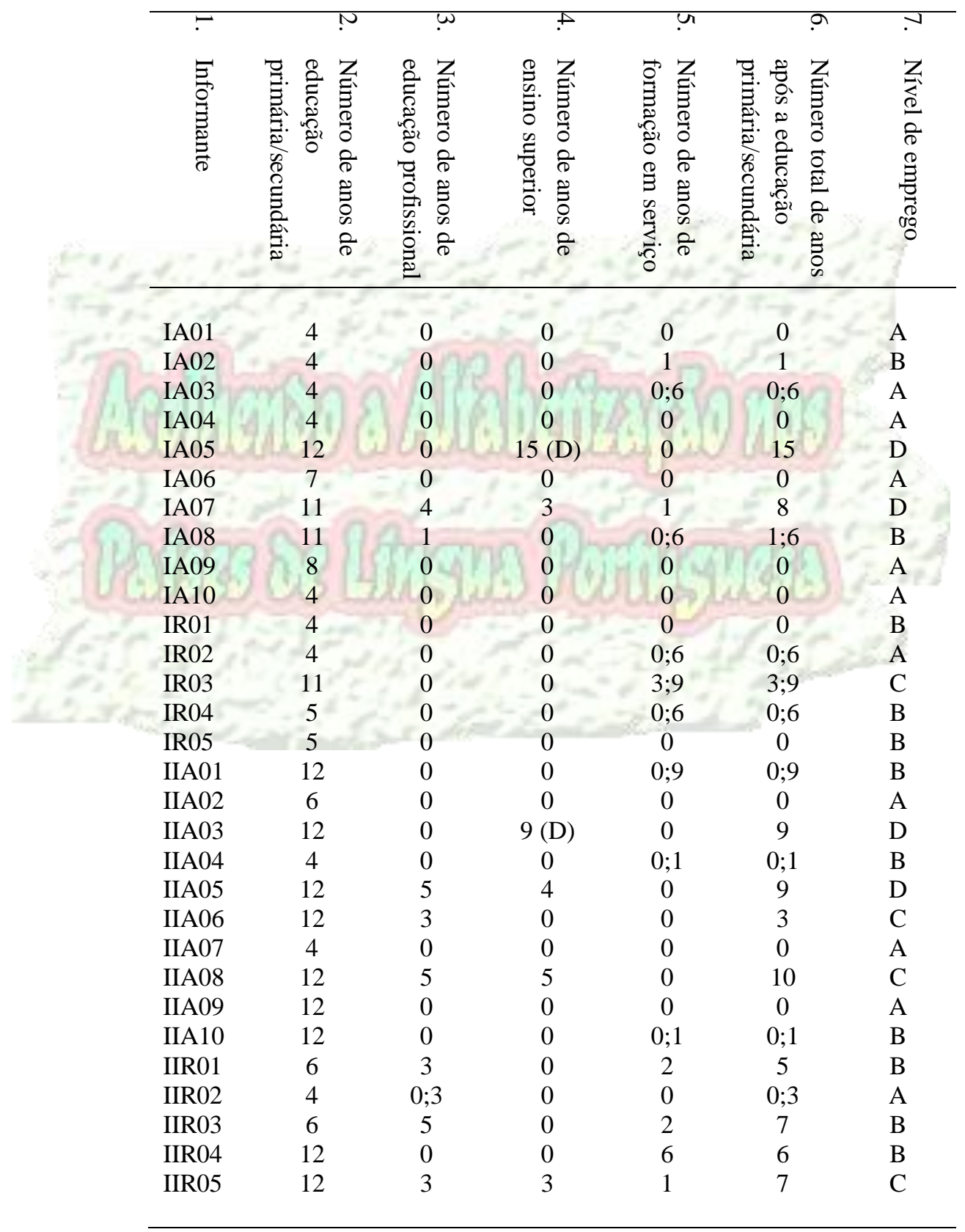




\subsection{Possíveis correlações}

Tendo em vista o objetivo deste trabalho, uma série de correlações são interessantes. Cabe aqui destacar que o número de informantes disponível para esta pesquisa não permite a aplicação de métodos estatísticos padrão. No entanto, os números são suficientemente significativos para possibilitar as conclusões abaixo:

- Há uma correlação entre o número de anos de educação primária/secundária (coluna 2) e o nível de emprego (coluna 7);

- Há uma correlação entre o número de anos de educação profissional (coluna 3) e o nível de emprego (coluna 7);

- Há uma correlação entre o número de anos de ensino superior (coluna 4) e o nível de emprego (coluna 7);

- Há uma correlação entre o número de anos de formação em șerviço (coluna 5) e o nível de emprego (coluna 7).

Os últimos três itens dizem respeito à correlação entre a educação voltada para a formação em uma profissão específica e um determinado nível de emprego; por essa razão faz sentido reagrupá-los. Assim, é possível reorganizar as correlações da seguinte forma:

- Há uma correlação entre o número de anos de educação primária/secundária (coluna 2) e o nível de emprego (coluna 7);

- Há uma correlação entre o número de anos de educação após e escola primária/secundária (coluna 6) e o nível de emprego (coluna 7).

São essas duas correlações que serão priorizadas nas próximas subseções.

\subsection{Educação primária/secundária e nível de emprego}

Para explorar a relação entre o número de anos de educação primária/secundária e o nível de emprego, os dados da Tabela 4 são organizados de maneira tal que seja possível mostrar uma ordem crescente 
na coluna 2. A subdivisão dentro de cada grupo toma como critério os valores contidos na coluna 6 .

Tabela 4 - Educação primária/secundária e nível de emprego

\begin{tabular}{|c|c|c|c|c|c|c|}
\hline 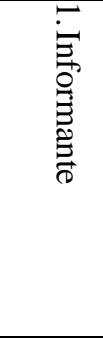 & 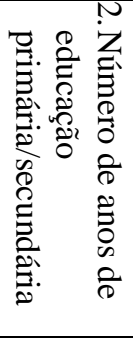 & 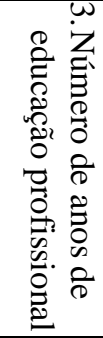 & 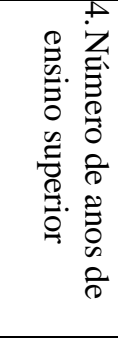 & 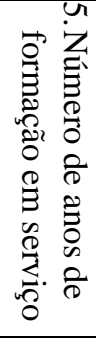 & 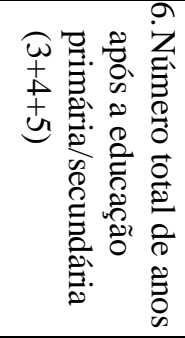 & $\begin{array}{l}2 \\
z \\
0 \\
0 \\
0 \\
0 \\
0 \\
0 \\
0 \\
0 \\
0\end{array}$ \\
\hline IA01 & 4 & 0 & 0 & 0 & 0 & A \\
\hline IA04 & 4 & 0 & 0 & 0 & 0 & $\mathrm{~A}$ \\
\hline IA10 & 4 & 0 & 0 & 0 & 0 & A \\
\hline IR01 & 4 & 0 & 0 & 0 & 0 & $\mathrm{~B}$ \\
\hline IIA07 & 4 & 0 & 0 & 0 & 0 & $\mathrm{~A}$ \\
\hline IIA04 & 4 & 0 & 0 & $0 ; 1$ & $0 ; 1$ & B \\
\hline IIR02 & 4 & $0 ; 3$ & 0 & 0 & $0 ; 3$ & $A$ \\
\hline IA03 & 4 & 0 & 0 & $0 ; 6$ & $0 ; 6$ & $A$ \\
\hline IR02 & 4 & 0 & 0 & $0 ; 6$ & $0 ; 6$ & $\mathrm{~A}$ \\
\hline IA02 & 4 & 0 & 0 & 1 & 1 & B \\
\hline IR05 & 5 & 0 & 0 & 0 & 0 & B \\
\hline IR04 & 5 & 0 & 0 & $0 ; 6$ & $0 ; 6$ & B \\
\hline IIA02 & 6 & 0 & 0 & 0 & 0 & A \\
\hline IIR01 & 6 & 3 & 0 & 2 & 5 & B \\
\hline IIR03 & 6 & 5 & 0 & 2 & 7 & B \\
\hline IA06 & 7 & 0 & 0 & 0 & 0 & A \\
\hline $\begin{array}{l}\text { IA09 } \\
\text { IA08 }\end{array}$ & $\begin{array}{l}8 \\
11\end{array}$ & $\begin{array}{l}0 \\
1\end{array}$ & & & $\begin{array}{l}0 \\
1 ; 6\end{array}$ & $\begin{array}{l}\text { A } \\
\text { B }\end{array}$ \\
\hline IR03 & 11 & 0 & 0 & $3 ; 9$ & $3: 9$ & $\mathrm{C}$ \\
\hline IA07 & 11 & 4 & 3 & 1 & 8 & $\mathrm{D}$ \\
\hline IIA09 & 12 & 0 & 0 & 0 & 0 & A \\
\hline IIA10 & 12 & 0 & 0 & $0 ; 1$ & $0 ; 1$ & B \\
\hline IIA01 & 12 & 0 & 0 & $0 ; 9$ & $0 ; 9$ & B \\
\hline IIA06 & 12 & 3 & 0 & 0 & 3 & $\mathrm{C}$ \\
\hline IIR04 & 12 & 0 & 0 & 6 & 6 & B \\
\hline IIR05 & 12 & 3 & 3 & 1 & 7 & $\mathrm{C}$ \\
\hline IIA03 & 12 & 0 & 9 (D) & 0 & 9 & D \\
\hline IIA05 & 12 & 5 & 4 & 0 & 9 & D \\
\hline IIA08 & 12 & 5 & 5 & 0 & 10 & C \\
\hline IA05 & 12 & 0 & 15 (D) & 0 & 15 & D \\
\hline
\end{tabular}

A: trabalho que consiste na execução de tarefas simples e rotineiras; B: que requer experiência e compreensão de um equipamento específico ou de um processo específico; $\mathrm{C}$ : que exige a compreensão de todas as etapas do processo de produção ou de administração; D: que é essencialmente de natureza científica ou intelectual. 
Os dados mostram uma correlação muito clara, uma vez que os informantes que não concluíram 11/12 anos de educação primária/secundária $^{1}$ têm, no máximo, um emprego de nível $\mathrm{B}$ e os informantes com empregos de níveis C e D nunca têm menos do que 11/12 anos de educação primária/secundária. Por outro lado, há informantes com empregos de níveis de emprego A e B que completaram 11/12 anos de educação primária/secundária. Esses resultados podem ser representados graficamente na Figura 1.

Figura 1 - Correlação entre anos de educação primária/secundária e nível de emprego

A: trabalho que consiste na execução de tarefas simples e rotineiras; B: que requer experiência e compreensão de um equipamento específico ou de um processo específico; C: que exige a compreensão de todas as etapas do processo de produção ou de administração; D: que é essencialmente de natureza científica ou intelectual,

Formulada de maneira diferente, a Figura 1 mostra que os informantes com emprego de níveis C e D nunca têm menos que 11/12 anos de educação primária/secundária, e que os que cursaram período inferiobr a 11/12 anos de educação primária/secundária nunca possuem empregos de níveis C e-Đ. Essa é uma conclusão já esperada para empregos de nível D, uma vez que empregos de natureza científica ou intelectual pressupõem formação superior, o que, por sua vez, implica a conclusão da educação primária/secundária.

Entretanto, essa conclusão não se aplica a empregos de nível $\mathrm{C}$ porque podem ser ocupados por indivíduos com formação profissional ou que realizaram formação em serviço, como demonstrado a seguir.

\footnotetext{
${ }^{1}$ Durante o período abrangido por este estudo, houve algumas mudanças no sistema educativo português. No que se refere ao número de anos da educação de base (primária e secundária), houve um aumento de 11 para 12 anos. Os informantes que concluíram 11/12 anos de escolaridade, referidos neste artigo, são os que realmente concluíram a educação primária e secundária, tanto em 11 quanto em 12 anos.
} 


\subsection{Educação após ensino primário/secundário e nível de emprego}

Para explorar as correlações entre o número de anos de formação após a conclusão da educação primária/secundária e o nível de emprego, os dados da Tabela 5 são organizados de tal maneira que se pode observar uma ordem crescente na coluna 6. A subdivisão dentro de cada grupo toma como critério os valores da coluna 2.

Tabela 5 - Formação após educação primária/secundária e nível de emprego

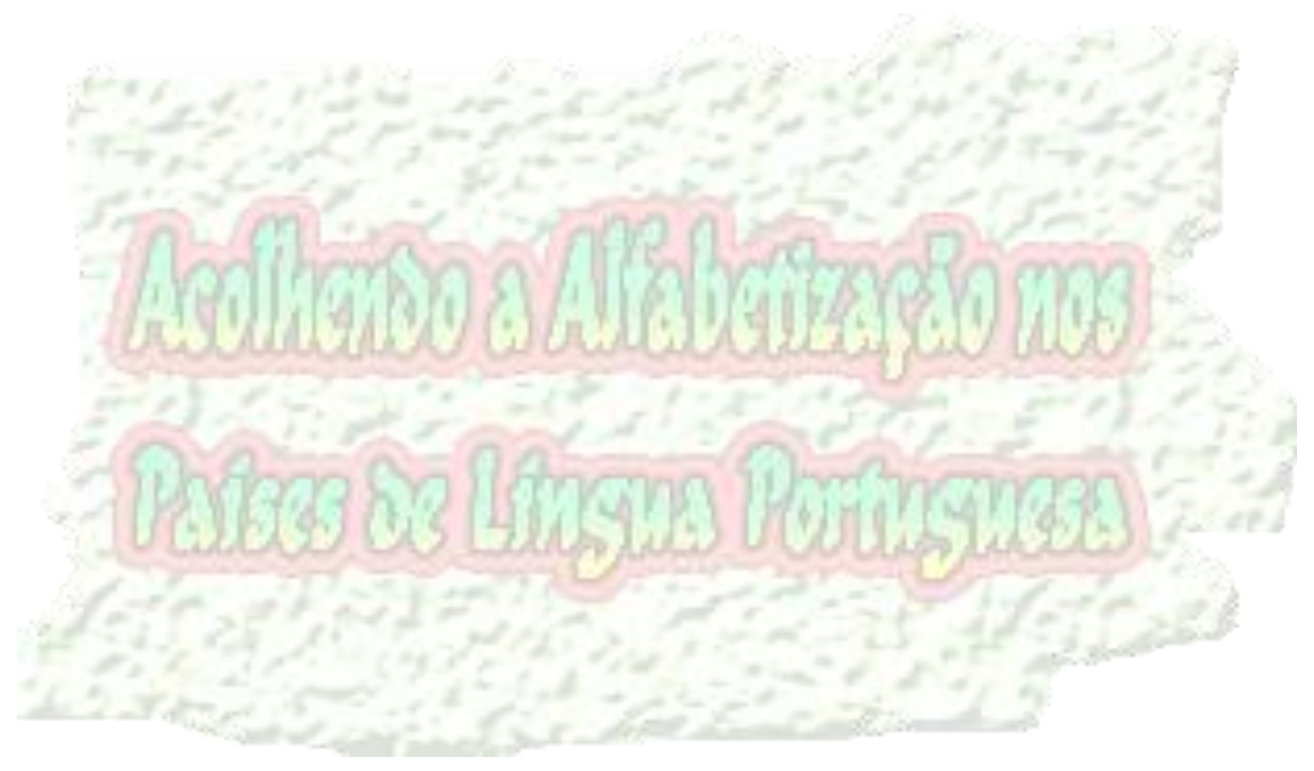




\begin{tabular}{|c|c|c|c|c|c|c|}
\hline 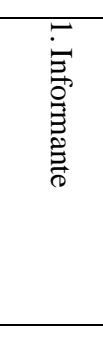 & 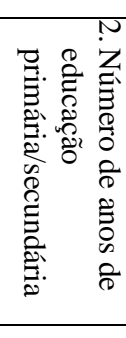 & 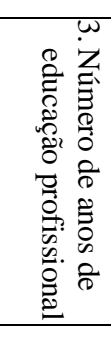 & 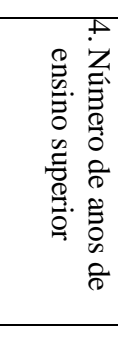 & 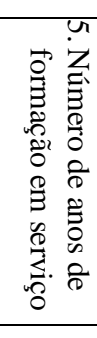 & 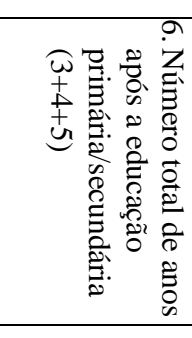 & 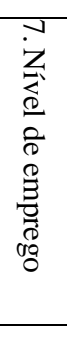 \\
\hline IA01 & 4 & 0 & 0 & 0 & 0 & A \\
\hline IA10 & 4 & 0 & 0 & 0 & 0 & A \\
\hline IR01 & 4 & 0 & 0 & 0 & 0 & B \\
\hline IIA07 & 4 & 0 & 0 & 0 & 0 & A \\
\hline IR05 & 5 & 0 & 0 & 0 & 0 & B \\
\hline IIA02 & 6 & 0 & 0 & 0 & 0 & A \\
\hline IA06 & 7 & 0 & 0 & 0 & 0 & A \\
\hline IA09 & 8 & 0 & 0 & 0 & 0 & A \\
\hline IIA09 & 12 & 0 & 0 & 0 & 0 & A \\
\hline IA04 & 4 & 0 & 0 & 0 & & $\mathrm{~A}$ \\
\hline IIA04 & 4 & 0 & 0 & $0 ; 1$ & $0 ; 1$ & B \\
\hline IIA10 & 12 & 0 & 0 & $0 ; 1$ & $0 ; 1$ & $B$ \\
\hline IIR02 & 4 & $0 ; 3$ & 0 & 0 & $0 ; 3$ & A \\
\hline IA03 & 4 & 0 & 0 & $0 ; 6$ & $0 ; 6$ & A \\
\hline IR02 & 4 & 0 & 0 & $0 ; 6$ & $0 ; 6$ & $\mathrm{~A}$ \\
\hline IR04 & 5 & 0 & 0 & $0 ; 6$ & $0 ; 6$ & $B$ \\
\hline IIA01 & 12 & 0 & 0 & $0 ; 9$ & $0 ; 9$ & B \\
\hline IA02 & 4 & 0 & 0 & $1 ; 0$ & $1 ; 0$ & B \\
\hline IA08 & 11 & 1 & 0 & $0 ; 6$ & $1 ; 6$ & B \\
\hline IIA06 & 12 & 3 & 0 & 0 & $3 ; 0$ & $\mathrm{C}$ \\
\hline IR03 & 11 & 0 & 0 & $3 ; 9$ & $3 ; 9$ & $\mathrm{C}$ \\
\hline IIR01 & 6 & 3 & 0 & $2 ; 0$ & $5 ; 0$ & B \\
\hline IIR04 & 12 & 0 & 0 & $6 ; 0$ & $6 ; 0$ & B \\
\hline IIR03 & 6 & 5 & 0 & $2 ; 0$ & $7 ; 0$ & $B$ \\
\hline IIR05 & 12 & 3 & 3 & $1 ; 0$ & $7 ; 0$ & $C$ \\
\hline IA07 & 11 & 4 & 3 & $1 ; 0$ & $8 ; 0$ & $\mathrm{D}$ \\
\hline IIA05 & 12 & 5 & 4 & 0 & $9 ; 0$ & $\mathrm{D}$ \\
\hline IIA03 & 12 & 0 & 9 (D) & 0 & $9 ; 0$ & $\mathrm{D}$ \\
\hline IIA08 & 12 & 5 & 5 & 0 & $10 ; 0$ & $\mathrm{C}$ \\
\hline IA05 & 12 & 0 & 15 (D) & 0 & $15 ; 0$ & D \\
\hline
\end{tabular}

A: trabalho que consiste na execução de tarefas simples e rotineiras; B: que requer experiência e compreensão de um equipamento específico ou de um processo específico; C: que exige a compreensão de todas as etapas do processo de produção ou de administração; D: que é essencialmente de natureza científica ou intelectual.

Os dados revelam novamente algumas correlações bastante claras, uma vez que os informantes que não completaram pelo menos três anos de formação após a educação primária/secundária não possuem empregos de níveis $\mathrm{C}$ e $\mathrm{D}$ e todos os informantes com oito anos de formação após a 
conclusão da educação primária/secundária possuem empregos de níveis $\mathrm{C}$ e D.

Nesse caso, porém, outras distinções podem ser observadas entre os empregos de níveis A e B e entre aqueles de níveis C e D. Quanto ao primeiro grupo, os informantes com empregos de nível A nunca tiveram mais de seis meses de educação depois da educação primária/secundária e aqueles com empregos de nível B tiveram até sete anos de formação após a conclusão da educação primária/secundária. Já quanto ao segundo grupo, os informantes com empregos de nível $\mathrm{C}$ podem ser encontrados dentre aqueles com formação entre três e dez anos após a educação primária/secundária e os que possuem empregos de nível D têm, pelo menos, oito anos de formação após a educação primária/secundária. Esses resultados podem ser representados graficamente na Figura 2.
$0 ; 6$
$3 ; 0$
$7 ; 0 \quad 8 ; 0$
$10 ; 0$
$15 ; 0$

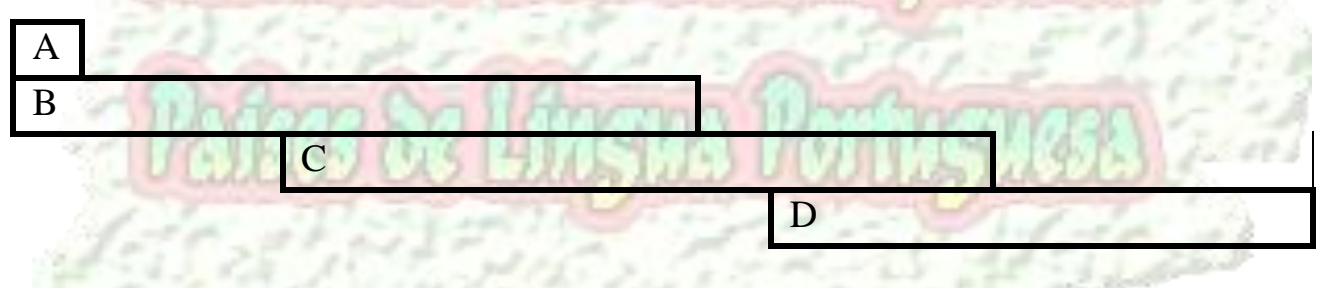

Figura 2 - Correlação entre a formação após a educação primária/secundáría e o nível de emprego

A: trabalho que consiste na execução de tarefas simples e rotineiras; B: que requer experiência e compreensão de um equipamento específico ou de um processo específico; C: que exige a compreensão de todas as etapas do processo de produção ou de administração; D: que é essencialmente de natureza científica ou intelectual.

É interessante observar que alguns informantes com poucos anos de educação primária/secundária e (quase) nenhuma formação posterior trabalham em empregos de nível B, como é o caso de IR01, IR05 e IIA04. Todos eles obtiveram um trabalho desse nível porque aprenderam uma profissão específica acumulando experiência durante o exercício do trabalho. 


\section{Conclusão}

Como pode ser mostrado neste trabalho, há certamente uma forte relação entre a formação educacional e a profissional e o sucesso no mercado de trabalho entre os imigrantes portugueses na Holanda. Fica claro que o nível de educação primária/secundária é bastante decisivo para a obtenção de empregos no que diz respeito ao conjunto de trabalhos $\mathrm{A} / \mathrm{B}$ e C/D. Tomando como ponto de comparação a educação que não fosse primária/secundária, vê-se que existe uma relação estreita entre o número de anos desse tipo de educação e o nível de trabalho obtido, o que demonstra que a formação dedicada especificamente à profissão interfere fortemẹte no percurso profissional. Os casos excepcionais confirmam essa conclusão porque mostram que a aprendizagem específica no emprego pode aumentar as possibilidades de ascensão no nível ocupacional.

\section{Referências bibliográficas}

ARROTEIA, J. C. A imigração portuguesa: suas origens e distribuição. Lisboa: ICALP, 1983.

CENTRAAL BUREAU VOOR DE STATISTIEK. Allochtonen in Nederland. Voorburg/Heerlen: Centraal Bureau voor de Statistiek, 19952007.

CENTRAAL BUREAU VOOR DE STATISTIEK. Allochtonen in Nederland 2004. Voorburg/Heerlen: Centraal Bureau voor de Statistiek, 2004.

FRANCO, A. S. A imigração para a Europa no conjunto da imigração portuguesa. Lisboa: Livraria Editora Pax, 1974.

GODINHO, V. M. L'Imigration Portugaise (XVe-XXe siécles). Une constante structurale et les Responses aux Changements du Monde. Revista de História Econômica e Social, Lisboa, n.1, p. 5-32, 1978. 
INTERNATIONAL MIGRATION OUTLOOK. OECD: SOPEMI Edition, 2008. Disponivel em: <http://www.oecd.org/dataoecd/30/13/41275373.pdf> Acesso em: 07 maio 2012.

\section{INTERNATION STANDARD CLASSIFICATION OF OCCUPATIONS.}

International Labour Organization, 1988. Disponível em: <http://www.ilo.org/public/english/bureau/stat/isco/index.htm>. Acesso em: 07 maio 2012.

LINDO, M. P. The silent succes. The social advancement of Southern European labour migrants in the Netherlands. In H. Vermeulen \& R. Penninx (Org.). Immigrant integration. The Dutch case. Amsterdam: Het Spinhuis, p. 123-152, 2000.

PEREIRA, M. H. A política portuguesa de imigração (1850 a 1930). Lisboa: A Regra do Jogo, 1981.

RIBEIRO, F. G. C. Emigração portuguesa: algumas características dominantes dos movimentos no período de 1950 a 1984. Porto: Secretaria de Estado das Comunidades Portuguesas. Centro de Estudos Série Migrações, 1986.

ROCHA-TRINDADE, M. B. A Imigração. Lisboa: Centro de Estudos Judiciários, 1986.

SERRR̃̃, J. A imigração portuguesa: sondagem histórica. 3. ed. Lişboa: Livros Horizonte, 1977. 


\section{AUTORA}

Silvana Fernandes LOPES

UNESP/São José do Rio Preto

Contato: silvanaflopes@gmail.com

Artigo recebido em fevereiro de 2012.

Aceito para publicação em março de 2012.

\section{Como citar este texto:}

LOPES, S. F. Formação educacional e profissional e sucesso no merçádo de trabalho: o caso dos imigrantes portugueses na Holanda. Revista Acolhendo a alfabetização nos países de língua portuguesa, Brasil, São Paulo, volume 1, $\mathrm{n}^{\mathrm{o}}$. 13, pp. 80 - 99, Set. 2012. Disponível em: <http://www.acoalfaplp.net>. 